\title{
Benefits of surgical intervention in locally advanced breast cancer - a Lynch II syndrome case presentation
}

\author{
Bogdan Socea ${ }^{1,2}$, Camelia Diaconu ${ }^{3,4}$, Ovidiu Gabriel Bratu ${ }^{5,6}$, Tiberiu Paul Neagu ${ }^{7,8}$, \\ Cristinel Dumitru Badiu', ${ }^{2,}$, Grigore Busoi ${ }^{10}$, Vlad Denis Constantin ${ }^{1,2}$ \\ ${ }^{1}$ Department of General Surgery, Emergency Clinical Hospital "Sf. Pantelimon", Bucharest, Romania \\ ${ }^{2}$ Clinical Department No. 10, "Carol Davila" University of Medicine and Pharmacy, \\ Bucharest, Romania \\ ${ }^{3}$ Department of Internal Medicine, Clinical Emergency Hospital of Bucharest, Romania \\ ${ }^{4}$ Clinical Department No. 5, "Carol Davila" University of Medicine and Pharmacy, Bucharest, Romania \\ ${ }^{5}$ Department of Urology, "Dr. Carol Davila" Central Military Emergency University Hospital, \\ Bucharest, Romania \\ ${ }^{6}$ Clinical Department No. 3, "Carol Davila" University of Medicine and Pharmacy, Bucharest, Romania \\ ${ }^{7}$ Department of Plastic Surgery and Reconstructive Microsurgery, Emergency Clinical Hospital of \\ Bucharest, Romania \\ ${ }^{8}$ Clinical Department No. 11, "Carol Davila" University of Medicine and Pharmacy, \\ Bucharest, Romania \\ ${ }^{9}$ Department of General Surgery, Emergency Clinical Hospital "Bagdasar Arseni", Bucharest, Romania \\ ${ }^{10}$ Family Medicine Office, Bucharest, Romania
}

\begin{abstract}
We present the case of a 82 years old women, who was admitted in our surgical clinic with two giant breast tumors, located on the left breast, with skin ulceration and suprainfection, accompanied by a big axillary mass in the left axilla.

The patient was known with a previous rectal tumor, recently operated in another surgical service, for which it was an anterior rectal resection and definitive left colostomy done.

The case is an atypical form of presentation of a Lynch II syndrome. The indication for total mastectomy and axillary lymphadenectomy was sustained by tumors' dimensions and suprainfection, although the case was oncologically overcome.
\end{abstract}

Keywords: Lynch II, breast cancer, rectal cancer

\section{INTRODUCTION}

Breast cancer is the most commonly occurring cancer in women and the second most common cancer overall. Colorectal cancer remains a significant cause of morbidity and mortality throughout the world. It accounts for about $10 \%$ of all cancer incidence (the third most common cancer worldwide) $(1,2)$.

In general population, synchronous malignant lesions are rare and have an incidence which varies between 0,17 and $0,69 \%(3,4)$. More than three or four concomitant malignant lesions are much more rare $(0,5 \%$ for three, resectivelly $0,1 \%$ for five $)$ $(5,6)$.

Lynch II syndrome gathers cases of human non-polyposic colorectal cancer associated with cancers of other locations. Cancers initially observed in significant excess in the first-degree relatives of Amsterdam criteria families included colorectal, endometrial, stomach, small intestine, prostate, kidney, and bladder cancer, as well as non-Hodgkin lymphoma. Endometriosis could even appear with colonic location (7). Some recent studies relieve higher risk for breast cancer in Lynch II relatives (8). 


\section{CASE PRESENTATION}

A 82-years old woman presented to our emergency room with multiple left breast and left axillary masses. It was obvious a neglected lesion. The tumors were skin ulcerating, with necrosion and suprainfection (Figures 1 and 2).
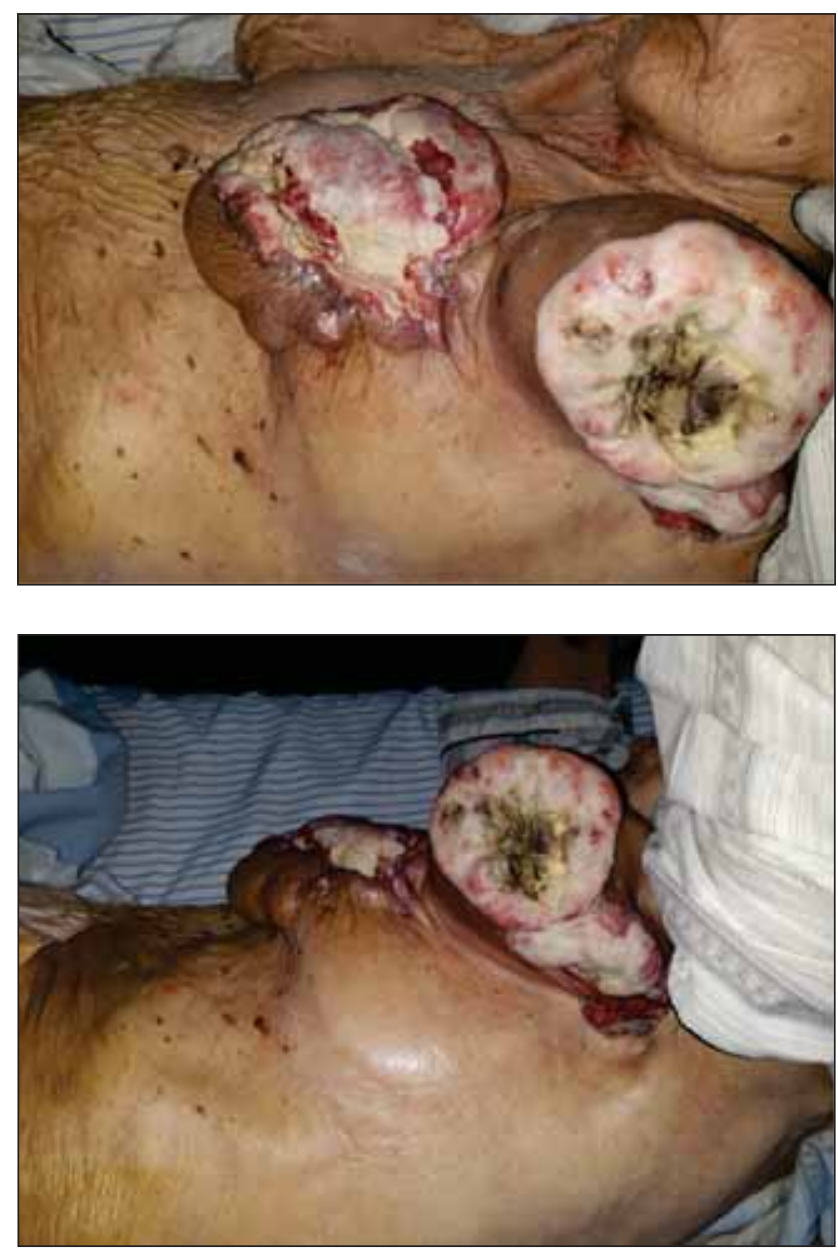

FIGURES 1 and 2: pre-operative outcome

The personal history noticed a rectal malignant tumor, operated two years ago in another surgical service. The surgical procedure was anterior rectal resection and left definitively, terminal colostomy for an acute pathology supposed to be a sigmoid intussusception (9). But the histopathologic result confirmed, at that time, moderately differentiated adenocarcinoma, for which the patient did no complementary oncologic treatment. Due to advanced age, the restoration of digestive transit has not been discussed either (10).

From the time interval point of view between rectal and breast tumors, we could consider their onset of a synchronous type.

The family history of the patient met the Amsterdam II criteria, after the polypoid origin of colorectal cancer for some family members was first excluded by colonoscopy (11).

The surgical indication was established to excise the infected tumors. Under general anesthesia, we did total mastectomy with axillary lymph nodes ablation, a current standard Madden radical mastectomy, a breast surgery that involves the ablation of tissue with the axillary lymphatic preserving both pectoral muscles. We could achieve negative margins. From the first description in 1972, Madden procedure became the current standard in radical mastectomy (12).

We did not need any skin plasty for covering the defect, since we could suture the skin without tension after a lateral subcutaneous dissection that mobilized more the skin edges. We placed a multiperforated drainage tube in the subcutaneous space, connected to an aspirative system. The post-operative outcome was with no complications. The active drainage system collected $100 \mathrm{ml}$ serous fluid in the first 24 hours, than $50 \mathrm{ml}$ daily for another 3 days. We suppressed the drain in day 4 . The patient was discharged in day 7 post-operatory (Figure 3).

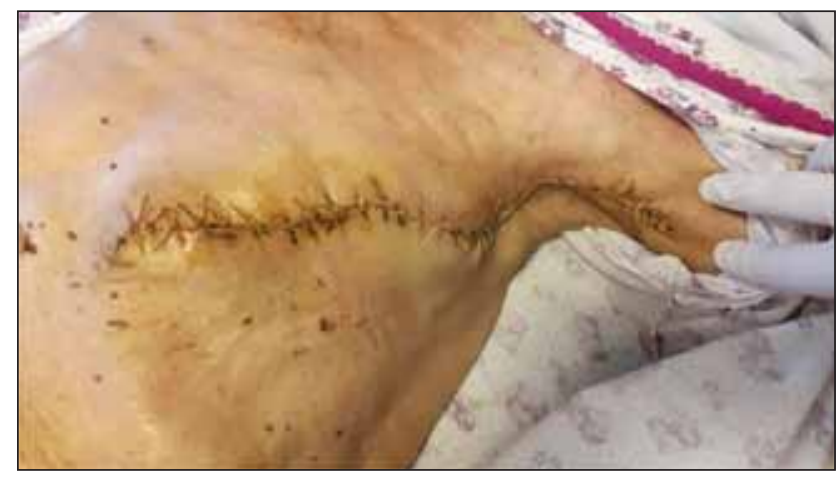

FIGURE 3. Post-operative outcome (day 7)

We suppressed the skin sutures two weeks after operation.

The histopathological result confirmed a moderately differentiated invasive ductal carcinoma and a massive carcinomatous axillary lymph node $(5 \mathrm{~cm}$ diameter).

Unfortunately, we could not perform genetic tests, nor for the patient, nor for other family members.

At one year follow-up visit no local recurrence could be observed, nor metastatic disease. The surgical result seem to be better than those reported in literature for skin ulcerated advanced breast cancer $(13,14)$. There are also some authors that had their first option for primary chemotherapy (15). 


\section{CONCLUSIONS}

Lynch II syndrome has a high risk for developing genital tumors in women, including ovarian, endometrial and also breast cancer.
Surgical excision proved to have a good outcome for locally advanced breast cancer at old age.

This is a rare case of association between rectal cancer and breast cancer in a Lynch II family, with an atypical old age of onset ( 80 years of age).

\section{Conflict of interest: none declared Financial support: none declared}

\section{REFERENCES}

1. Boyle $P$, Langman JS. $A B C$ of colorectal cancer: Epidemiology. BMJ. 2000; 321(7264):805-8.

2. Păun I, Constantin VD, Socea B, Bobic S. The impact of environmental factors upon the incidence rate of colorectal cancer. Ciencia e Tecnica Vitivinicola 2015; 30/2 (11):99-133.

3. Lasser A. Synchronous primary adenocarcinomas of the colon and rectum. Dis Colon Rectum. 1978; 21(1): 20-2.

4. Luciani A, Balducci L. Multiple primary malignancies. Semin Oncol. 2004; 31(2): 264-273.

5. Németh Z, Czigner J, Iván L, Ujpál M, Barabás J, Szabó G. Quadruple cancer, including triple cancers in the head and neck region. Neoplasma. 2002; 49(6): 412-414.

6. Curtis RE, Freedman DM, Ron E, Ries LAG, Hacker DG, Edwards BK, Tucker MA, Fraumeni JF Jr. (eds). New Malignancies Among Cancer Survivors: SEER Cancer Registries, 1973-2000. National Cancer Institute. NIH Publ. No. 05-5302. Bethesda, MD, 2006.

7. Constantin VD, Carâp AC, Bobic S, Păun I, Brătilă E, Socea B, Moroşanu AM, Mirancea N. Accurate diagnosis of sigmoid colon endometriosis by immunohistochemistry and transmission electron microscopy - a case report. Chirurgia 2015; 110(5):482-485.

8. Goldberg M, Bell K, Aronson M, Semotiuk K, Pond G, Gallinger S, Zbuk K. Association between the Lynch syndrome gene MSH2 and breast cancer susceptibility in a Canadian familial cancer registry. J Med Genet. 2017;54(11):742-746.
9. AA, Bratu OG, Diaconu CC, Smaranda AC, Socea LI, Bertesteanu SVG, Dimitriu MCT, Carap AC, Constantin VD. Incidental finding of a sigmoid intussusception associated with rectal prolapse - A case report. Arch Balk Med Union 2018; 53(1):143-6.

10. Socea B, Bratu OG, Diaconu CC, Socea LI, Dimitriu M, Carap A, Nica AA, Smaranda A, Moculescu CE, Baleanu VD, Davitoiu D, Constantin VD. Does colostomy restoration increase the risk of developing a subsequent rectal cancer? Arch Balk Med Union 2018; 53(3):369-372.

11. Dimitriu CV, Dimitriu L, Voiculescu S, Kraft A, Socea B, Burcoş T. Recent acquisitions in the endoscopic treatment of colorectal lesions. Arch Balk Med Union 2014; 49(4):490-495.

12. Madden JL, Kandalaft S, Bourque RA. Modified radical mastectomy. Ann Surg. 1972;175(5):624-634.

13. Laforgia R, Punzo C, Panebianco A, Volpi A, Minafra M, Sederino MG. Surgical approach for ulcerated locally advanced breast cancer. A single Center experience: a retrospective study. Ann Ital Chir. 2017;88. pii: S0003469X1702615X.

14. Khoury T, Gaudioso C, Fang YV, Sanati S, Opyrchal M, Desouki MM, Karabakhtsian RG, Li Z, Wang D, Yan L, Jacobson R. The role of skin ulceration in breast carcinoma staging and outcome. Breast $\mathrm{J}$. 2018;24(1):41-50.

15. Sasaki Y, Okuyama M, Hibino M, Tenma K, Nakamura M. A case of elderly locally-advanced breast cancer with skin ulcer responding to letrozole. Gan To Kagaku Ryoho. 2012 Jun;39(6):1005-8. 